\title{
Photochemistry of Formic Acid Monomer at 222 nm*
}

\author{
ROBERT S. IRWIN, ${ }^{\dagger}$ DONALD L. SINGLETON, \\ GEORGE PARASKEVOPOULOS, and ROBERT MCLAREN \\ Institute for Environmental Chemistry, National Research Council \\ Ottawa, Ontario, Canada K1A OR6
}

\begin{abstract}
The yields of $\mathrm{CO}_{2}$ and $\mathrm{CO}$ formed from the gas-phase photolysis at $222 \mathrm{~nm}$ of very low pressures of formic acid where the monomer predominates have been determined using FTIR spectroscopy. The observed ratio of $\mathrm{CO}_{2} / \mathrm{CO}$ approaches unity as the formic acid pressure approaches zero. Previous studies have shown that the quantum yield for $\mathrm{HCOOH}+h \nu \rightarrow \mathrm{OH}+\mathrm{HCO}$ (or $\mathrm{H}+\mathrm{CO}$ ) is 0.70 at $298 \mathrm{~K}$. The present experimental results indicate that the ratio of the quantum yields of the possible molecular photolysis channels forming $\mathrm{H}_{2}+\mathrm{CO}_{2}\left(\phi_{1 \mathrm{~b}}\right)$ and $\mathrm{H}_{2} \mathrm{O}+\mathrm{CO}\left(\phi_{1 \mathrm{c}}\right)$ is ca. 1. Including this result in an analysis of previously reported quantum yields of $\mathrm{CO}$ and $\mathrm{CO}_{2}$ determined at higher pressures of formic acid, where both monomer and dimer contribute significantly to the products, indicates that $\phi_{1 \mathrm{~b}}=\phi_{1 \mathrm{c}}=0$. (c) 1994 John Wiley \& Sons, Inc.
\end{abstract}

\section{Introduction}

The gas-phase photochemistry of organic acids is highly dependent on the nature of the acid. The results of photolysis in the $n-\pi^{*}$ band of $\alpha$ - and $\beta$-dicarbonyl acids (oxalic, malonic, glyoxylic, and pyruvic acid), which involve internal hydrogen bonding, have been interpreted by Robert Back and co-workers as involving internal $\mathrm{H}$ atom transfer to generate a hydroxycarbene or dihydroxycarbene [1-5]. For example, the major route in the photolysis of glyoxylic acid is believed to involve the internal transfer of an acidic hydrogen atom to the $\alpha$-dicarbonyl oxygen and formation of $\mathrm{CO}_{2}$ and the hydroxymethylene, $\mathrm{HCOH}$, which rearranges primarily to $\mathrm{H}_{2} \mathrm{CO}$ [3].

In contrast to the $\alpha$-dicarbonyl acids, the photolysis of the monomers of the simple alkanoic acids (formic, acetic, and propionic acid) involves formation of $\mathrm{OH}$ radicals, with the quantum yield decreasing with increasing size of the acid [6]. Photolysis of the hydrogen bonded dimers forms very little or no $\mathrm{OH}$, and may proceed through a molecular mechanism. The $\mathrm{OH}$ radicals formed in the photolysis undergo secondary reactions with the organic acid under usual experimental conditions. Furthermore, photodecomposition of both the monomer and the dimer can give the same stable products, but in different proportions, and the presence of significant concentrations of both the monomer and dimer of formic acid during the experiments can lead to ambiguity in identifying the photolysis channels and the subsequent reactions. As a result, it is difficult from stable product analysis alone to differentiate the products

\footnotetext{
*This article is dedicated to the memory of our friend and colleague at the National Research Council, Dr. Robert A. Back.

† Passed away July 16, 1993, after more than 30 years of contributions to scientific research at the National Research Council.
} 
of the photolysis from the products of the secondary reactions without additional information [7].

In the case of formic acid, a significant amount of data has been determined. We have determined the quantum yield of $\mathrm{OH}$ formed as a primary product in the photolysis of the monomer $(\phi=0.70 \pm 0.05$ at $298 \mathrm{~K})$ and dimer $(\phi=0.15 \pm 0.03$ at $298 \mathrm{~K})$ of formic acid at $222 \mathrm{~nm}$ using a kinetic spectroscopic technique $[6,8]$. The quantum yields of the stable products, $\mathrm{CO}$ and $\mathrm{CO}_{2}$ were also determined [7] for formic acid pressures in the range 0.5 to 26 torr. The rate constants have been determined for the reaction of $\mathrm{OH}$ with the monomer $\left(k=4.5 \times 10^{-13} \mathrm{~cm}^{3} \mathrm{molec}^{-1} \mathrm{~s}^{-1}\right.$ at $\left.297 \mathrm{~K}\right)$ and dimer $\left(8.0 \times 10^{-14} \mathrm{~cm}^{3} \mathrm{molec}^{-1} \mathrm{~s}^{-1}\right.$ at $\left.297 \mathrm{~K}\right)$ of formic acid $[9,10]$, and $\mathrm{H}$ atoms have been identified as a product of the reaction of $\mathrm{OH}$ with $\mathrm{HCOOH}$ with a yield of $0.75 \pm 0.25$ [11].

Even with these data it has not been possible to assign a unique mechanism to the photolysis of formic acid, and assumptions have been made concerning the photolytic channels of the monomer and dimer that do not involve formation of $\mathrm{OH}$ [7], which can have quantum yields of up to 0.30 and about 0.85 , respectively, if radiative and nonradiative relaxation processes are not important. In selecting possible products for these channels to fit the observed yields of $\mathrm{CO}_{2}$ and $\mathrm{CO}$, it was assumed that $\mathrm{CO}_{2}$ and $\mathrm{CO}$ could be formed from the dimer, but not from the monomer, in order to reduce the number of adjustable parameters. Attempts to verify these assumptions by extending the determination of stable product yields to sufficiently low pressures so that only the monomer contributes significantly to the photochemistry were not successful because of the large uncertainty of the gas chromatographic determination of very small yields of $\mathrm{CO}$ and $\mathrm{CO}_{2}$. In the present work, we have used FTIR spectroscopy to measure the small amounts of $\mathrm{CO}$ and $\mathrm{CO}_{2}$ formed at low formic acid concentrations. This technique provides greater sensitivity than our previous measurements using gas chromatography, and permits extension of the measurements to very low formic acid pressures where the monomer constitutes 90-98\% of the vapor phase acid composition. The results provide further information on the photodecomposition channels of the monomer.

\section{Experimental}

Gas mixtures were prepared in a cell with White optics providing a $20 \mathrm{~m}$ optical path for the infra-red analyzing beam and a $1.5 \mathrm{~m}$ optical path for the uv laser photolyzing beam, with a base path of $0.375 \mathrm{~m}$ (Wilks Foxboro). The walls of the cell were Teflon coated. Aluminum surfaced mirrors were used for the White cell to provide adequate reflection efficiency in the ir and uv regions. The volume of the cell was 5.41. Formic acid was photolyzed at $222 \mathrm{~nm}$ using a $\mathrm{KrCl}$ excimer laser (Lumonics 860 ) with typical optical pulse energies within the White cell of $4 \mathrm{~mJ}$ at a repetition rate of $10 \mathrm{~Hz}$. Products of the photolysis were analyzed with a FTIR spectrometer (Bomem DA-8) at an apodized resolution of $0.16 \mathrm{~cm}^{-1}$, averaging 30 scans.

Formic acid was measured directly in the cell, and the total pressure was brought to 800 torr by addition of nitrogen. Pressure measurements were made with $0-10$ torr and 0-1000 torr capacitance manometers. The experiments were done at a temperature of $297.5 \pm 1.0 \mathrm{~K}$. Formic acid (98\%, with the remainder water) was obtained from Aldrich and was degassed by several freeze-pump-thaw cycles. UHP grade nitrogen from Linde was passed through Oxisorb to remove any trace levels of oxygen. 
Selection of the ir absorption bands for quantitative analysis was based on the optimum range of absorbance values for the experimental conditions. Absorption spectra were obtained by ratioing to the spectrum of the evacuated cell. The consumption of formic acid was determined quantitatively by spectral subtraction of the absorption spectra before and after photolysis, using the absorption peaks at $1758 \mathrm{~cm}^{-1}\left(\nu_{3}\right.$, carbonyl stretch) or at $2158 \mathrm{~cm}^{-1}$ (overtone of $\nu_{6}, \mathrm{C}-\mathrm{O}$ stretch). The photolysis products, $\mathrm{CO}$ and $\mathrm{CO}_{2}$, were determined from the areas of the peaks at $2099 \mathrm{~cm}^{-1}$ (P11) and $2321 \mathrm{~cm}^{-1}$ (P16), respectively. Calibration mixtures for CO and $\mathrm{CO}_{2}$ were made by expanding known amounts into the cell.

\section{Results}

A slow nonphotochemical loss of $\mathrm{HCOOH}$ was observed by FTIR which was firstorder in formic acid over the measured range of $0.015-0.046$ torr. The first-order rate constant, $d[\mathrm{HCOOH}] / d t=-k[\mathrm{HCOOH}]$, was $2.2 \times 10^{-5} \mathrm{~s}^{-1}$. The total loss of formic acid during a photolysis experiment was small, ranging from $2 \%$ to $6 \%$, and the photochemical and dark reaction losses were comparable. An attempt was made to correct the overall loss of formic acid, determined by the observed decrease in ir absorption, for the thermal loss, and to compare the photochemical loss of formic acid with the yield of $\mathrm{CO}$ and $\mathrm{CO}_{2}$. However, because the calculation of the ratio $\left([\mathrm{CO}]+\left[\mathrm{CO}_{2}\right]\right) /(\Delta[\mathrm{HCOOH}])$ involved a small difference between large numbers, the results were not meaningful because of the high uncertainty in the ratio and the considerable scatter in the values.

For very long residence times in the cell without photolysis, a trace of $\mathrm{CO}_{2}$ was observed with a formation rate of about $5 \times 10^{8}$ molecules $\mathrm{cm}^{-3} \mathrm{~s}^{-1}$. The $\mathrm{CO}_{2}$ observed during photolysis was corrected for this source, and the average correction was $1.6 \%$. If the source of the $\mathrm{CO}_{2}$ was from a leak of atmospheric air into the cell, the presence of oxygen could potentially have a more serious effect on the product yields, due to the formation of $\mathrm{HO}_{2}$ and reformation of $\mathrm{OH}$ under certain conditions as discussed below. However, this is unlikely because the cell was typically at slightly higher pressure than ambient.

In the initial phase of this work, photolysis experiments resulted in erratic and sometimes high values of $\mathrm{CO}_{2} / \mathrm{CO}$. Passing the nitrogen used as the buffer gas through an Oxisorb trap to remove trace levels of oxygen resulted in more consistent values of $\mathrm{CO}_{2} / \mathrm{CO}$.

The FTIR spectra from a typical experiment are shown in Figure 1. The absorbance spectra labelled $A$ and $B$ were obtained before and after photolysis with 4800 laser pulses of 0.086 torr of formic acid in 807 torr of $\mathrm{N}_{2}$. Multiplication of spectrum $A$ by 0.97 and subtraction of the product from $B$ results in removal of the formic acid band in the region of $2198 \mathrm{~cm}^{-1}$, leaving only the $\mathrm{CO}$ and $\mathrm{CO}_{2}$ bands, as shown in $\mathrm{C}$. The ratio of $\mathrm{CO}_{2} / \mathrm{CO}$ in this experiment was 1.03 .

The ratio $\mathrm{CO}_{2} / \mathrm{CO}$ tended to decrease slightly with increasing extent of photolysis, especially for more than about 6000 laser pulses. This effect tended to be more important at higher concentrations of formic acid. For example, for 0.11-0.12 torr of formic acid, the average value of $\mathrm{CO}_{2} / \mathrm{CO}$ for four experiments with 2400-4800 laser pulses was 0.83 , and for three experiments with 7200-15000 laser pulses, the value of the ratio was 0.64 . The reason for this effect is not clear. Computer simulations indicated that the reaction $\mathrm{OH}+\mathrm{HCO}$ could account for only a few percent of the 


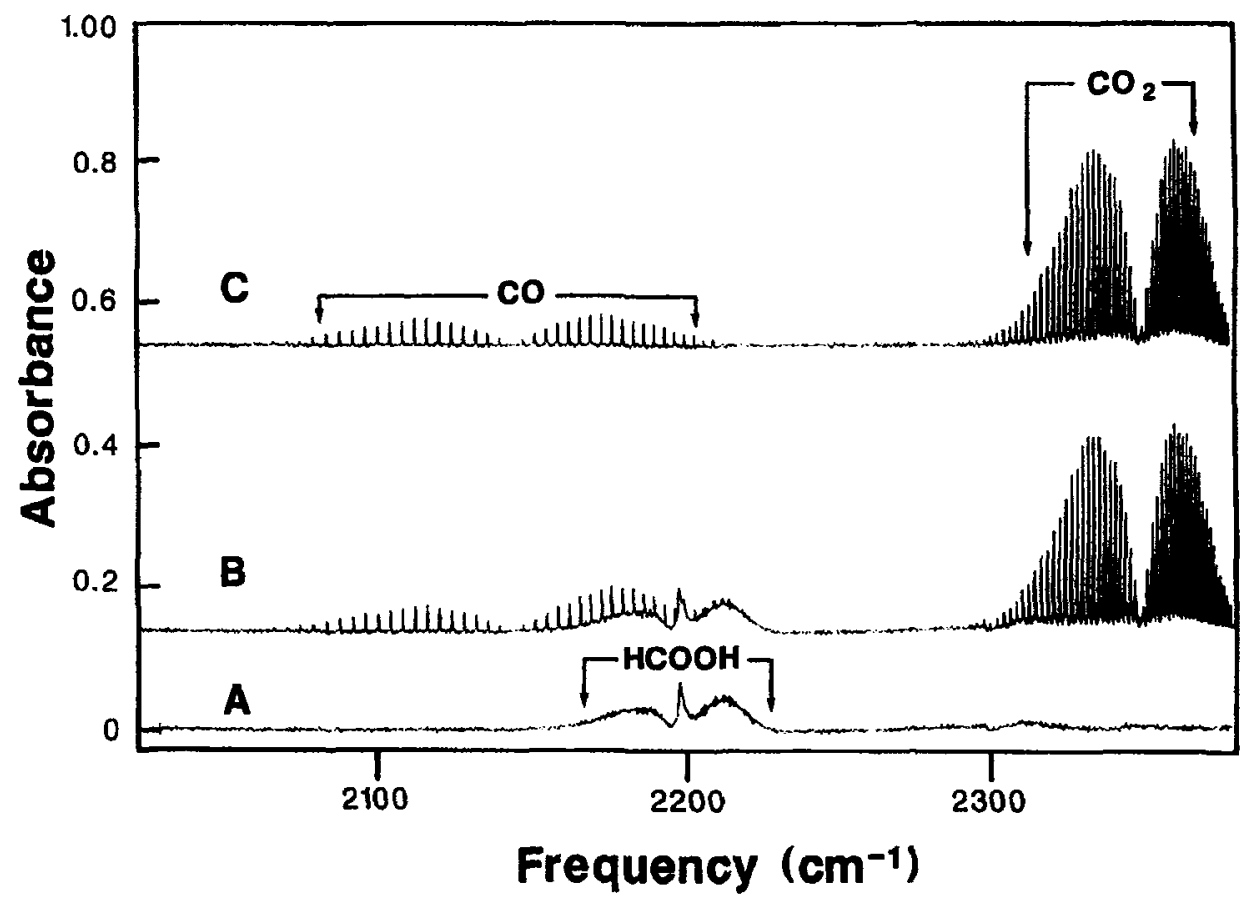

Figure 1. Absorbance spectra of 0.086 torr of formic acid in 807 torr of $\mathrm{N}_{2}$ : (A) prior to photolysis; (B) after photolysis with 4800 laser pulses of $4 \mathrm{~mJ}$ per pulse in the cell; and (C) the result of subtracting $97 \%$ of the absorbance of Spectrum (A) from Spectrum (B).

observed reduction in the $\mathrm{CO}_{2} / \mathrm{CO}$ ratio. The data selected for analysis did not include long photolysis times.

The values of the ratio $\mathrm{CO}_{2} / \mathrm{CO}$ are presented in Figure 2. The percentage of dimer present in the FTIR experiments in Figure 2 ranged from 1.6\% to 10\%. Also shown are the values of $\mathrm{CO}_{2} / \mathrm{CO}$ reported previously [7] that were determined by gas chromatographic analysis for higher formic acid concentrations, where the dimer ranged from $18 \%$ to $75 \%$. The calculations of monomer and dimer composition were based on the equilibrium constant of $6.5 \times 10^{16}$ molecule $/ \mathrm{cm}^{3}$ at $297 \mathrm{~K}$ taken from ref. [12] as discussed previously [10].

\section{Discussion}

The objective of the present work was to determine the yields of $\mathrm{CO}$ and $\mathrm{CO}_{2}$ in the photolysis of sufficiently low concentrations of formic acid that complications arising from photolysis and subsequent reactions of the dimer were not significant. The present results in Figure 2 show that as the formic acid pressure is reduced, the value of the ratio $\mathrm{CO}_{2} / \mathrm{CO}$ approaches unity. Potential photolytic channels for the monomer are shown in Table I. The present results exclude the two potential extreme combination of values for $\phi_{1 \mathrm{~b}}$ and $\phi_{1 \mathrm{c}}$, namely, $\phi_{1 \mathrm{~b}}=0$ and $\phi_{1 \mathrm{c}}=0.3$,or $\phi_{1 \mathrm{~b}}=0.3$ and $\phi_{1 \mathrm{c}}=0$. In the former case, the limiting value of $\mathrm{CO}_{2} / \mathrm{CO}$ would be 1.4 , and in the latter case, 0.7 . The results are consistent with $\phi_{1 \mathrm{~b}} \simeq \phi_{1 \mathrm{c}}$, and if relaxation processes were insignificant, $\phi_{1 \mathrm{~b}} \simeq \phi_{1 \mathrm{c}}<0.15$, although it is not possible to determine the absolute values from the present data alone. 


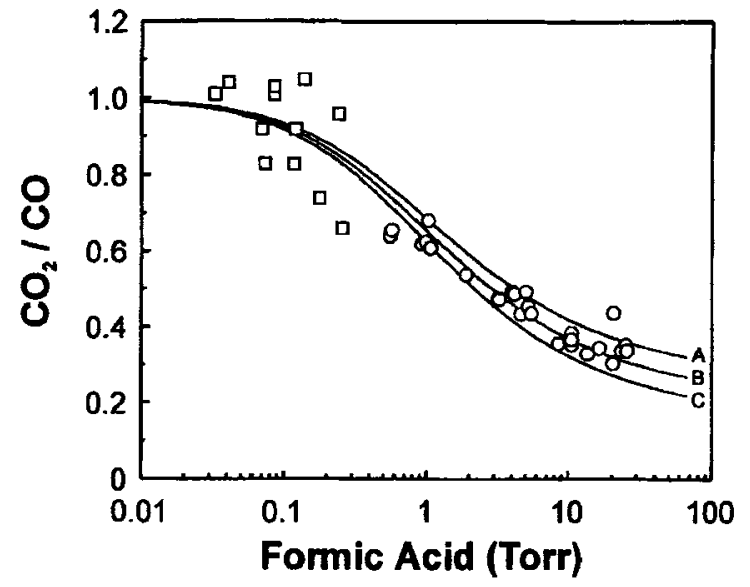

Figure 2. Yield of the ratio $\mathrm{CO}_{2} / \mathrm{CO}$ as a function of formic acid pressure. ( $\square$ ) determined in the present study by FTIR and $(O)$ determined previously by gas chromatography [7]. The lines are calculated for three different values of $\phi_{2 b} /\left(\phi_{2 b}+\phi_{2 c}\right):(A) 0.90 ;(B) 0.95$; and (C) 1.0 .

TABLE I. Reactions proposed for the photochemical reactions of formic acid at $222 \mathrm{~nm}$.

\begin{tabular}{|c|c|c|c|c|}
\hline & & Reaction & Quantum Yield & Ref. \\
\hline $\begin{array}{l}(1 \mathrm{a}) \\
\left(1 a^{\prime}\right) \\
(1 \mathrm{~b}) \\
(1 \mathrm{c})\end{array}$ & $\mathrm{HCOOH}+h v$ & $\begin{array}{l}\rightarrow \mathrm{OH}+\mathrm{H}+\mathrm{CO} \\
\rightarrow \mathrm{OH}+\mathrm{HCO} \\
\rightarrow \mathrm{H}_{2} \mathrm{O}+\mathrm{CO} \\
\rightarrow \mathrm{H}_{2}+\mathrm{CO}_{2}\end{array}$ & $\begin{array}{l}\phi_{1 \mathrm{a}}+\phi_{1 \mathrm{a}^{\prime}}=0.70 \\
\phi_{1 \mathrm{~b}}=0.0 \\
\phi_{1 \mathrm{c}}=0.0\end{array}$ & {$[6]$} \\
\hline $\begin{array}{l}(2 a) \\
(2 b) \\
(2 c)\end{array}$ & $(\mathrm{HCOOH})_{2}+h v$ & $\begin{array}{l}\rightarrow \mathrm{OH}+\mathrm{HCO}+\mathrm{HCOOH} \\
\rightarrow \mathrm{H}_{2} \mathrm{O}+\mathrm{CO}+\mathrm{HCOOH} \\
\rightarrow \mathrm{H}_{2}+\mathrm{CO}_{2}+\mathrm{HCOOH}\end{array}$ & $\begin{array}{l}\phi_{2 \mathrm{a}}=0.15 \\
\phi_{2 \mathrm{~b}}=0.8 \\
\phi_{2 \mathrm{c}}=0.05\end{array}$ & $\begin{array}{l}{[6]} \\
{[7]} \\
{[7]}\end{array}$ \\
\hline $\begin{array}{l}(3) \\
(4) \\
(5) \\
(6)\end{array}$ & $\begin{array}{l}\mathrm{OH}+\mathrm{HCOOH} \\
\mathrm{OH}+(\mathrm{HCOOH})_{2} \\
\mathrm{H}+\mathrm{HCO} \\
\mathrm{H}+\mathrm{H}+\mathbf{M}\end{array}$ & $\begin{array}{l}\rightarrow \mathrm{H}_{2} \mathrm{O}+\mathrm{H}+\mathrm{CO}_{2} \\
\rightarrow \mathrm{H}_{2} \mathrm{O}+\mathrm{H}+\mathrm{CO}_{2}+\mathrm{HCOOH} \\
\rightarrow \mathrm{H}_{2}+\mathrm{CO} \\
\rightarrow \mathrm{H}_{2}+\mathrm{M}\end{array}$ & $k_{3} / k_{4}=5.57$ & [9] \\
\hline
\end{tabular}

Previously, we had modelled the quantum yields for formation of $\mathrm{CO}_{2}$ and of $\mathrm{CO}$ as well as the ratio $\mathrm{CO}_{2} / \mathrm{CO}$ using the mechanism and data in Table I [7]. The values of the quantum yields in Table $I$ for reactions $1 a, 1 a^{\prime}$, and $2 a$ and of the rate constants for reactions 3 and 4 were determined by spectroscopic observation of $\mathrm{OH}$. The yield of $\mathrm{H}$ atoms in reaction $3,0.75 \pm 0.25$ was determined by spectroscopic observation of $\mathrm{H}$ [11]. The values of $\mathrm{CO}_{2} / \mathrm{CO}$ calculated using the mechanism in Table I are plotted in Figure 2 for three different ratios of $\phi_{2 \mathrm{~b}} /\left(\phi_{2 \mathrm{~b}}+\phi_{2 \mathrm{c}}\right)$, with the best fit obtained for $\phi_{2 \mathrm{~b}} /\left(\phi_{2 \mathrm{~b}}+\phi_{2 \mathrm{c}}\right)=0.95$. Further details on the calculation are given in ref. [7]. ${ }^{1}$

It was recognized in the previous work that the mechanism was not unique in terms of fitting the data at high pressures of formic acid where photolysis and reactions of both monomer and dimer could be significant [7]. In particular, it was assumed that $\phi_{1 \mathrm{~b}}$ and $\phi_{1 \mathrm{c}}$ were negligible, and that the quantum yield $\phi_{2 \mathrm{~b}}+\phi_{2 \mathrm{c}}$ was 0.85 .

\footnotetext{
${ }^{1}$ There was a small error in the calculation of the fitted lines presented in Figure 3 of ref. [7]. The lines in Figure 2 of the present article were calculated correctly.
} 
The assumed mechanism could adequately account for the observed $\mathrm{CO}_{2} / \mathrm{CO}$ ratio if $\phi_{2 \mathrm{~b}} /\left(\phi_{2 \mathrm{~b}}+\phi_{2 \mathrm{c}}\right)=0.95$. These values also provided a reasonable fit to the observed quantum yields of $\mathrm{CO}$ and $\mathrm{CO}_{2}$. The present results, which indicate that $\phi_{1 \mathrm{~b}} \simeq \phi_{1 \mathrm{c}}$, are consistent with this mechanism. Furthermore, calculations using larger values of $\phi_{1 \mathrm{~b}}=\phi_{1 \mathrm{c}}=0.15$ and smaller values of $\phi_{2 \mathrm{~b}}=0.75$ and $\phi_{2 \mathrm{c}}=0$ give slightly poorer fits to the experimental quantum yields of $\mathrm{CO}$ and of $\mathrm{CO}_{2}$ reported in ref. [7].

A steady state analysis of the mechanism in Table I leads to the equations

$$
\begin{aligned}
& \phi_{\mathrm{CO}} \cong\left[\left(\phi_{1 \mathrm{~b}}-\phi_{2 \mathrm{~b}}\right)+\left(\phi_{1 \mathrm{a}}-\phi_{2 \mathrm{a}}\right)\right] \alpha+\left(\phi_{2 \mathrm{a}}+\phi_{2 \mathrm{~b}}\right) \\
& \phi_{\mathrm{CO}_{2}} \cong\left[\left(\phi_{1 \mathrm{c}}-\phi_{2 \mathrm{c}}\right)+\left(\phi_{1 \mathrm{a}}-\phi_{2 \mathrm{a}}\right)\right] \alpha+\left(\phi_{2 \mathrm{a}}+\phi_{2 \mathrm{c}}\right)
\end{aligned}
$$

where $\alpha$ is the fraction of the total absorbed light that is absorbed by the monomer. Although the steady state approximation is not necessarily appropriate for the pulsed laser experiments, the equations serve to indicate how the various quantum yields are inter-related. A least-squares fit of these equations to the previously reported data for $\phi_{\mathrm{CO}}$ and $\phi_{\mathrm{CO}_{2}}$ results in equal but slightly negative values of ca. -0.1 for $\phi_{1 \mathrm{~b}}$ and $\phi_{1 \mathrm{c}}$, assuming the values of quantum yields in Table $I$. The values have large standard deviations, and are consistent with $\phi_{1 \mathrm{~b}}=\phi_{1 \mathrm{c}}=0$. All of these observations indicate that $\phi_{1 \mathrm{~b}}=\phi_{1 \mathrm{c}}=0$, in which case formation of $\mathrm{OH}$ and relaxation processes are the major channels of reaction 1 .

The dominance of reaction $2 \mathrm{~b}$ over $2 \mathrm{c}$ parallels the results for thermal decomposition of formic acid, including infra-red multiphoton decomposition [13], and the results of theoretical calculations [14,15] which indicate a slightly lower activation energy for the channel forming $\mathrm{CO}$ and $\mathrm{H}_{2} \mathrm{O}$ from the monomer than for the channel forming $\mathrm{H}_{2}$ and $\mathrm{CO}_{2}$.

We also carried out a computer simulation of the effect of oxygen impurity on the yields of $\mathrm{CO}_{2}$ and $\mathrm{CO}$ as a result of our observations regarding the $\mathrm{CO}_{2} / \mathrm{CO}$ yields with and without passing the nitrogen gas through Oxisorb. Under certain conditions, the presence of oxygen can lead to a chain reaction as follows.

$$
\begin{aligned}
\mathrm{OH}+\mathrm{HCOOH} & \longrightarrow \mathrm{H}_{2} \mathrm{O}+\mathrm{CO}_{2}+\mathrm{H} \\
\mathrm{H}+\mathrm{O}_{2}+\mathrm{M} & \longrightarrow \mathrm{HO}_{2}+\mathrm{M} \\
\mathrm{H}+\mathrm{HO}_{2} & \longrightarrow 2 \mathrm{OH}
\end{aligned}
$$

The simulations included the reactions in Table I along with reactions involving $\mathrm{H}$, $\mathrm{HO}_{2}, \mathrm{OH}$, and $\mathrm{O}$. The initial concentration of $\mathrm{OH}$ per laser pulse was estimated from the measured yield of $\mathrm{CO}_{2}$, taking into account the photolytic volume of the White cell. The simulations showed that relatively small concentrations of oxygen can have a significant effect on the $\mathrm{CO}_{2} / \mathrm{CO}$ ratio, for example $\mathrm{CO}_{2} / \mathrm{CO}=1.8$ for 0.08 torr of formic acid and $1 \times 10^{-4}$ torr of $\mathrm{O}_{2}$ (i.e., ca. $0.1 \mathrm{ppm} \mathrm{O}_{2}$ in 800 torr of $\mathrm{N}_{2}$ ). There is a relatively narrow range of oxygen concentrations where this effect is observed. At high concentrations of oxygen, nearly all the $\mathrm{H}$ atoms are scavenged by $\mathrm{O}_{2}$, thus averting regeneration of $\mathrm{OH}$. At very low concentrations of $\mathrm{O}_{2}$, other reactions effectively compete for $\mathrm{H}$ atoms. In the range of oxygen concentrations over which the simulations indicated an increase in the $\mathrm{CO}_{2} / \mathrm{CO}$ ratio, the magnitude of the increase depended on the number of laser pulses, since there was significant consumption of oxygen under these conditions. The simulations indicate that the results would not be affected by sufficiently low or high pressures of $\mathrm{O}_{2}$ impurity, and the former approach was adopted in the present work. Although efforts were made to minimize oxygen impurities, it was not possible to verify the concentration of $\mathrm{O}_{2}$ in the reaction cell, 
and the possibility remains that trace levels of $\mathrm{O}_{2}$ may have affected the results. If so, the observed $\mathrm{CO}_{2} / \mathrm{CO}$ ratios would be too large, in which case the results would indicate that the quantum yield for channel $1 b$ would be greater than that of $1 c$.

\section{Bibliography}

[1] S. Yamamoto and R. A. Back, J. Phys. Chem., 89, 622 (1985).

[2] R.A. Back, Can. J. Chem., 62, 1414 (1984).

[3] R. A. Back and S. Yamamoto, Can. J. Chem., 63, 542 (1985).

[4] S. Yamamoto and R. A. Back, Can. J. Chem., 63, 549 (1985).

[5] J.-R. Cao and R.A. Back, Can. J. Chem., 64, 967 (1986).

[6] D. L. Singleton, G. Paraskevopoulos, and R. S. Irwin, J. Phys. Chem., 94, 965 (1990).

[7] D. L. Singleton, G. Paraskevopoulos, and R. S. Irwin, Res. Chem. Intermed., 12, 1 (1989).

[8] G.S. Jolly, D. L. Singleton, and G. Paraskevopoulos, J. Phys. Chem., 91, 3463 (1987).

[9] D. L. Singleton, G. Paraskevopoulos, R. S. Irwin, G. S. Jolly, and D. J. McKenney, J. Amer. Chem. Soc., 110, 7786 (1988).

[10] G.S. Jolly, D. J. McKenney, D. L. Singleton, G. Paraskevopoulos, and A. R. Bossard, J. Phys. Chem., 90, 6557 (1986).

[11] P. H. Wine, R. J. Astalos, and R. L. Maulding, III, J. Phys. Chem., 89, 2620 (1985).

[12] J. O. Halford, J. Chem. Phys., 10, 582 (1942).

[13] R. Corkum, C. Willis, and R. A. Back, Chem. Phys., 24, 13 (1977).

[14] J.D. Goddard, Y. Yamaguchi, and H. F. Schaefer III, J. Chem. Phys., 96, 1158 (1992),

[15] J.S. Francisco, J. Chem. Phys., 96, 1167 (1992).

Received March 2, 1993

Accepted August 26, 1993 